\title{
Surgical Treatment of Central Giant Cell Granuloma with Carnoy's Solution
}

\author{
Miguel Ángel Garcés-Villalá1* ${ }^{*}$, Sergio David Rico1, Mariano Escudero-Pinel1, \\ José Luis Calvo-Guirado²
}

${ }^{1}$ Department of Implant and Biomaterial Research, Fundación Corazón de Jesús, San Juan, Argentina

${ }^{2}$ Department of Oral Surgery and Implant Dentistry, Faculty of Health Sciences, Universidad Católica San Antonio de Murcia, Murcia España

Email: ^fundacioncorazondejesus@gmail.com, davidricoodonto@yahoo.com.ar, escuderopinel@gmail.com, jlcalvo@ucam.edu

How to cite this paper: Garcés-Villalá, M.Á., Rico, S.D., Escudero-Pinel, M. and Calvo-Guirado, J.L. (2020) Surgical Treatment of Central Giant Cell Granuloma with Carnoy's Solution. Journal of Biosciences and Medicines, 8, 67-78.

https://doi.org/10.4236/jbm.2020.88007

Received: July 10, 2020

Accepted: August 10, 2020

Published: August 13, 2020

Copyright (อ 2020 by author(s) and Scientific Research Publishing Inc. This work is licensed under the Creative Commons Attribution International License (CC BY 4.0).

http://creativecommons.org/licenses/by/4.0/

(c) (i) Open Access

\begin{abstract}
A 25-year-old woman presented a unilateral mandibular swelling, after laboratory analysis, radiological studies and aspiration puncture biopsy, the pathological diagnosis of Central Giant Cell Granuloma was made. Radiographically, the multilocular lesion involved the left lower first molar and was $30 \mathrm{~mm}$ long by $20 \mathrm{~mm}$ high. Dental extraction of the molar involved with forceps and exeresis in toto of the tumor were performed using a Volkmann cutting curette. The tumor made up of $90 \%$ vascular tissue produced intra-surgical bleeding that made visibility difficult. The bone bed curettage was aggressive except for its base in direct contact with the inferior dental nerve. Subsequently, to avoid recurrence, the surgical protocol includes a double irrigation with Carnoy's solution, (fixative composed of $60 \%$ ethanol, $30 \%$ chloroform and $10 \%$ glacial acetic acid $98 \%$ ) for 5 minutes that produces chemical cauterization. Finally, it was washed with physiological solution and the cavity was filled with iodoformed gauze. The gauze was exchanged and removed gradually over three weeks for second intention healing. This case is presented to demonstrate that inexpensive chemical treatment can be safely used for outpatient surgery under local anesthesia. Because Carnoy's solution achieved control of intraoperative bleeding, allowed bone healing and prevented recurrence of the lesion in clinical radiographic follow-up for 15 years.
\end{abstract}

\section{Keywords}

Central Giant Cell Granuloma, Carnoy’s Solution, Conservative Surgical Treatment

\section{Introduction}

In the histological classification of odontogenic and maxillofacial bone tumors of 
O.M.S. of the year 2005 [1] the "Central giant cell granuloma" (CGCG) is recognized within the category of benign tumors: lesions related to bone and in the new classification of the year 2017 within the category of "Giant cell lesions and bone cysts" [2]. Giant cell lesions are a group of various pathologies of unknown etiology, poorly understood and with difficult diagnosis, due to the fact that they present similar clinical and histological characteristics. They are made up of fibrous tissue that contains multiple foci of hemorrhage, aggregation of multinucleated giant cells, and occasionally presents trabeculae of immature bone tissue [3]. CGCL is more frequent in the mandible with a jaw/maxilla ratio of 2:1, [3] [4] in the area of anterior teeth up to the first molar [4] [5] [6]. In the case of the age group, it mainly affects children or young adults under 30 years of age, very frequent in the female gender [7] [8] [9].

We present a clinical case of a 25 -year-old female patient with a radiolucent lesion located in the left side of the mandible, the first molar area. The objective of the present work was to show an effective way of solving the clinical case and monitoring its evolution during a long follow-up time.

\section{Case Report}

A female patient comes to the consultation because she notices a hard lump in her mandible in the left first molar area, which is slow growing and without previous trauma. The molar has vitality without mobility and painless percussion. Intraorally, effacement of the vestibular sulcus is observed in the molar area (see Figure 1(b). On palpation there is no expansion of the cortical bone plate that remains integral, although there is pressure sensitivity. Extraoral examination revealed gross asymmetry shown in Figure 1(a). All vital signs were within normal limits. Diagnosis was performed by X-ray images with orthopantomography, frontal, occlusal and lateral presented in Figure 2. A multilocular lesion with osteolytic zones and slight radiopacity was observed in the margins but without completely delimiting them and the root apices retained their integrity. Pathological entities compatible with radiological images were considered for differential diagnosis of odontogenic keratocyst, ameloblastoma, central giant cell granuloma, ameloblastic fibroma, ossifying fibroma and odontogenic myxoma.

Analysis of serum alkaline phosphatase (172 IU/L) and urinary hydroxyproline $(20.3 \mathrm{mg} / 24 \mathrm{~h})$ that were within normal parameters were performed to rule out Paget's disease and hyperparathyroidism (brown tumor) pathologies with similar radiological images.

After local anesthesia, a closed biopsy was taken by puncture-aspiration with a thick needle (CNB) of the site of interest to have a certain diagnosis through pa-thological study. The needle was inserted trying to insert it into the center of the injury. When the needle reaches the lesion, its contents are aspirated by suction. This is repeated to ensure that you have obtained an appropriate and usable quantity. Sample processing was performed by simple extension between glass slides fixation with $96 \%$ ethanol and drying, 14 sheets of samples were obtained. Staining 
was carried out using the Papanicolaou and May Grünwald-Giemsa techniques. In order to facilitate teamwork, the request for a report to the pa-thologist must

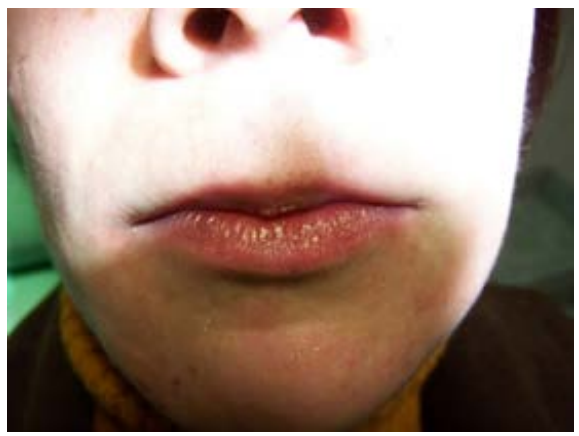

(a)

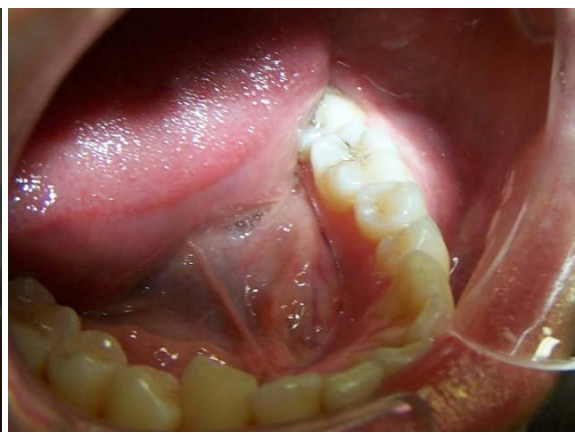

(b)

Figure 1. (a) Extraoral photograph shows mandibular swelling on the left side; (b) Intraoral photograph of the lesion with effacement of the vestibular sulcus in the area of the first molar.

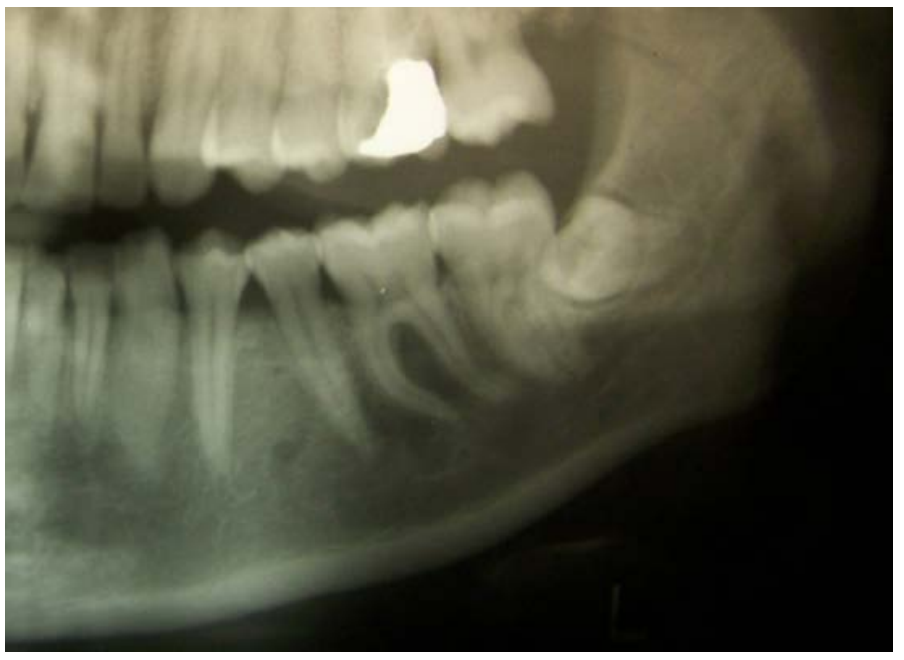

(a)

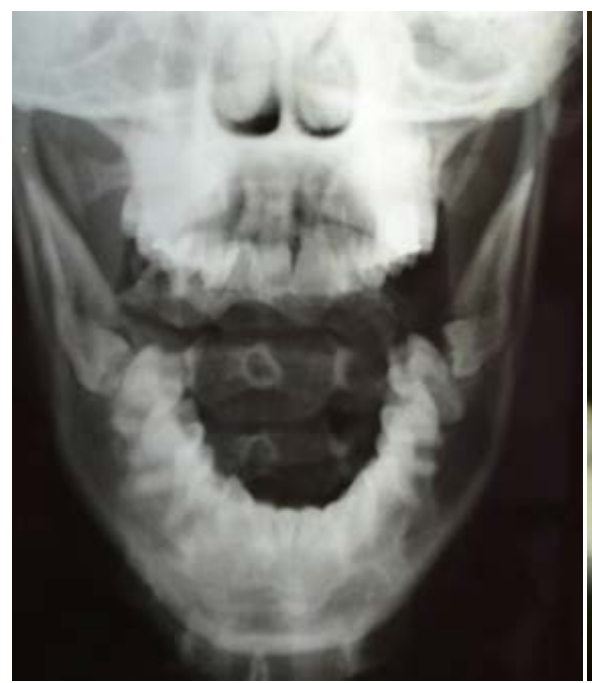

(b)

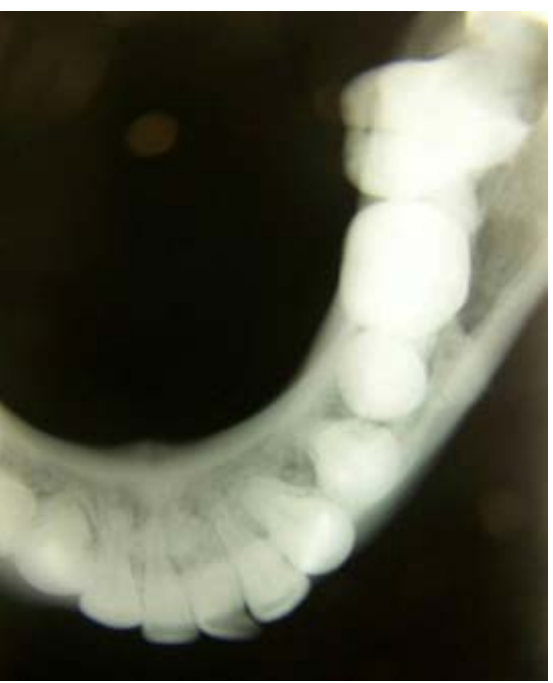

(c) 


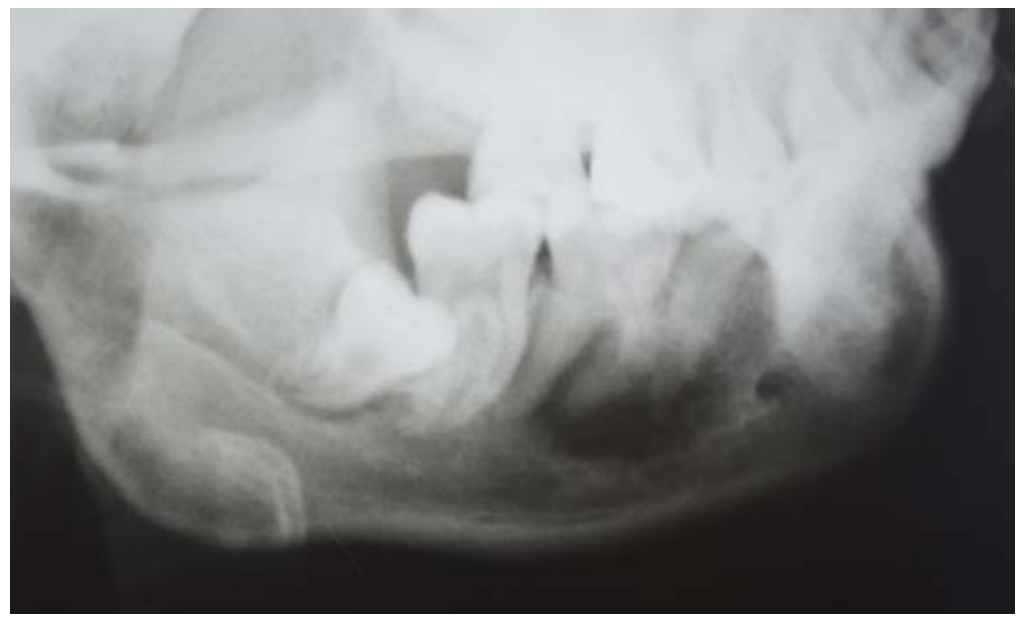

(d)

Figure 2. Previous X-rays: (a) Orthopantomography; (b) Frontal; (c) Occlusal; (d) Lateral.

include, in addition to the photographs and radiographs, personal data, age, sex, evolution time: symptoms (pain-paresthesia-sensitivity-etc), extension, surface condition, mobility and location, possible differential diagnoses and specific queries on the type of epithelium and degree of dysplasia.

In the CNB cytopathological study, hemorrhagic material was observed, consisting of very abundant multinucleated giant histiocytes with a large pleomorphic cytoplasm, showing numerous and large vesicular nuclei with a single prominent acidophilic nucleolus. Isolated mononucleated histiocytic cells, lymphocytes, and scattered plasmacytes are also observed. Absence of epithelial cells (ameloblastoma is ruled out). Atypical elements are not observed. Cytopathological diagnosis: Central giant cell granuloma.

\section{Surgery and Pathology}

Surgery is planned after obtaining the pathology report. The surgical protocol begins with anti-inflammatory antibiotic premedication and local anesthesia. A wide mucoperiosteal flap from mesial of the first premolar to distal of the second molar allows visualization of the surgical field. Tooth extraction of the first involved molar is performed with forceps and then the vestibular bone cortex is removed with a handpiece and round burr to gain access to the tumor mass. An irregular tumoral mass was found in the body of the left jaw. It was soft and had a dark red surface, and the distal edge of the mass was connected and abundantly vascularized by the mandibular bone. With the Volkmann cutting curette, the exeresis of the entire tumor mass that can be seen in Figure 3 was quickly performed. In these highly vascular lesions, intraoperative bleeding during curettage is abundant. Therefore irrigation of the surgical site or the buffered with gauze soaked for 5 minutes with Carnoy's solution, which produces chemical cauterization, helps to inhibit bleeding. Carnoy's solution consists of: $300 \mathrm{ml}$ of Chloroform, $100 \mathrm{ml}$ of $98 \%$ acetic acid and $600 \mathrm{ml}$ of alcohol. Then a profuse 


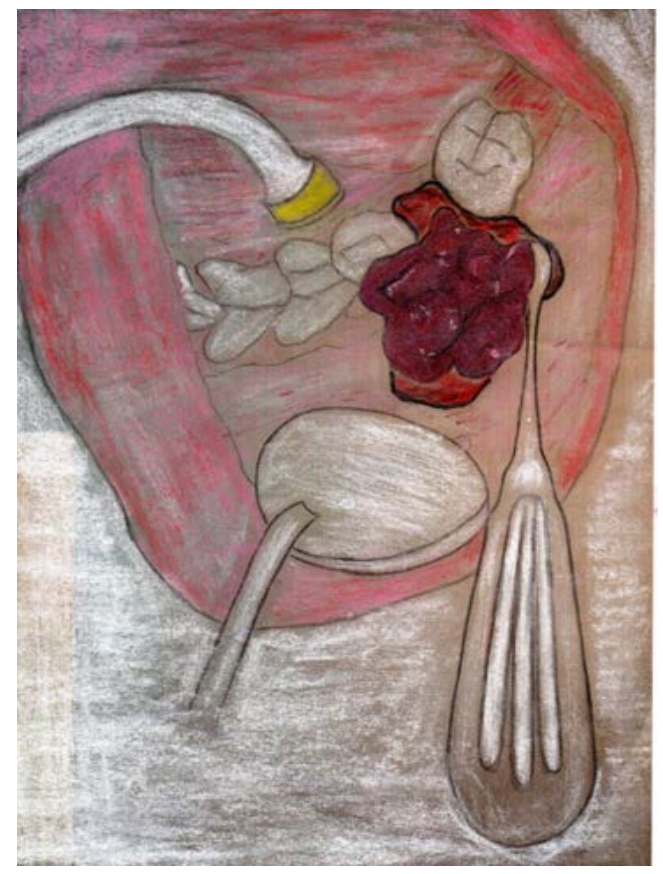

Figure 3. Illustration of tumor excision with Volkmann's cutting curette.

washing with physiological solution and powerful aspiration was performed, so as not to injure the surrounding tissues. The curettage operation is repeated, checking all the walls of the cavity to finish removing the remaining tumor tissue remains. Wash with physiological solution and aspirate again to irrigate or buffer with Carnoy's solution for an additional 5 minutes to fix and destroy residual tissue from injury. Subsequently, a last wash of the cavity is carried out with physiological solution and aspiration to remove excess fixative. Tumor mass showing the lower lobes of the tumor visible in the multilocular image of the postoperative orthopantomography in close contact with the lower dental nerve (Figure 4). After extraction of the involved molar, interradicular tumor tissue and the integrity of the root apices can be seen in Figure 5(a). Finally, the cavity is filled with an iodoformed gauze visible in Figure 5(b) which is gradually removed for second intention healing. Excisional biopsy of the tumor macroscopically shows the $2.7 \times 1.9 \times 0.9 \mathrm{~cm}$ tumor fragment with soft and fleshy areas that alternate with brownish-gray areas with soft or friable cut hemorrhages. The histological technique was paraffin inclusion with semi-serial cuts of the specimen and staining with hematoxylin-eosin (HE).

Microscopy: The study of the sections shows a tumor lesion composed of a stroma consisting of a regular amount of fibrous cell spindle tissue with large, normochromic, vesicular or optically empty nuclei with one or two inconspicuous acidophilic nucleoli. In more cellular areas the elements are rounded or oval, they show a sparse basophilic cytoplasm, also a rich capillary vascularization and very few mitoses. Interspersing this tissue, a large number of multinucleated giant elements of homogeneous or slightly granular cytoplasm are observed, presenting numerous nuclei identical to stromal cells, generally grouped 


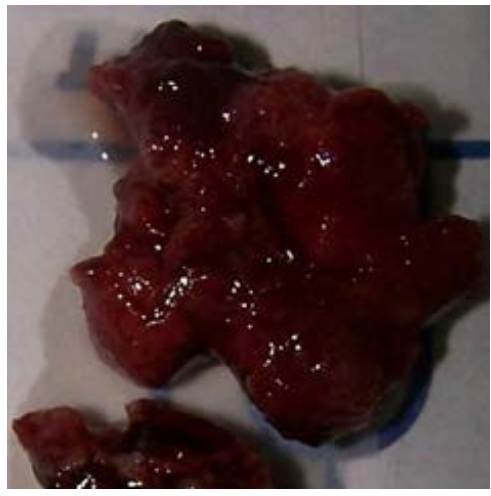

(a)

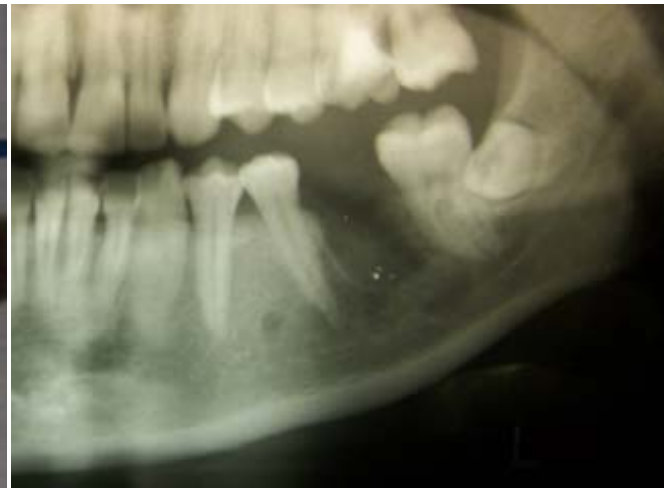

(b)

Figure 4. (a) Tumor mass showing the lower lobes of the tumor visible in the multilocular image of the postoperative orthopantomography in close contact with the lower dental nerve (b).

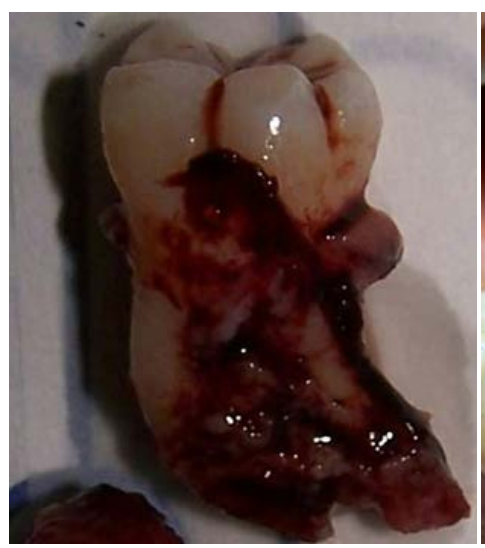

(a)

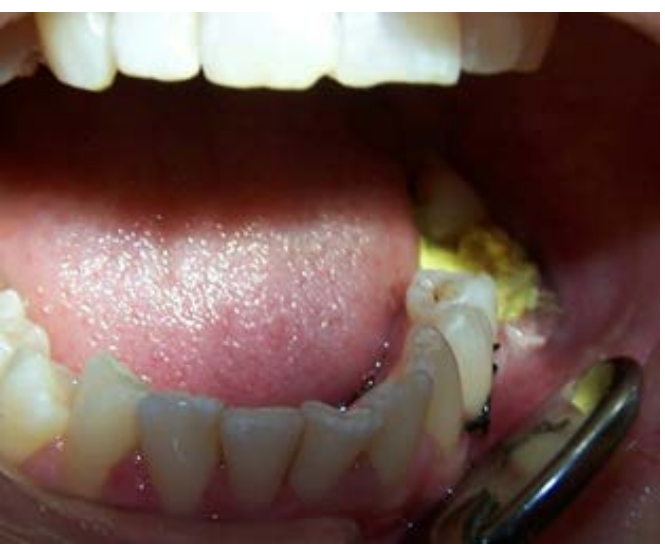

(b)

Figure 5. (a) Molar involved with interradicular tumor tissue and integrity of the root apices. (b) Filling of the cavity with iodoformed gauze and suture of the flap.

in the center of the cytoplasm, with an osteoclastoid appearance. Focal bleeding areas and few regressive fibrous areas are observed. Some partially reabsorbed trabeculae are located in the middle of the tumor stroma. xanthomatous histiocytic elements are not observed. The tumor vascularization is intense, generally formed by neoformed capillaries with a wall exclusively composed of endothelial elements, in indistinguishable places, in such a way that they appear to be vascular channels covered by the tumor elements. In sectors a spindle cell differentiation with intercellular collagen and few giant cells is seen in quantity, a frequent aspect found in the central giant cell granuloma (Figure 6).

In the immediate postoperative period, there was a normal second intention cure (Figure 7) and in the clinical and radiological follow-up for 15 years presented in Figures 8-10, no signs of recurrence were observed.

\section{Discussion}

CGCG is a rare lesion representing $<7 \%$ of all benign tumors of the jaw [10]. 


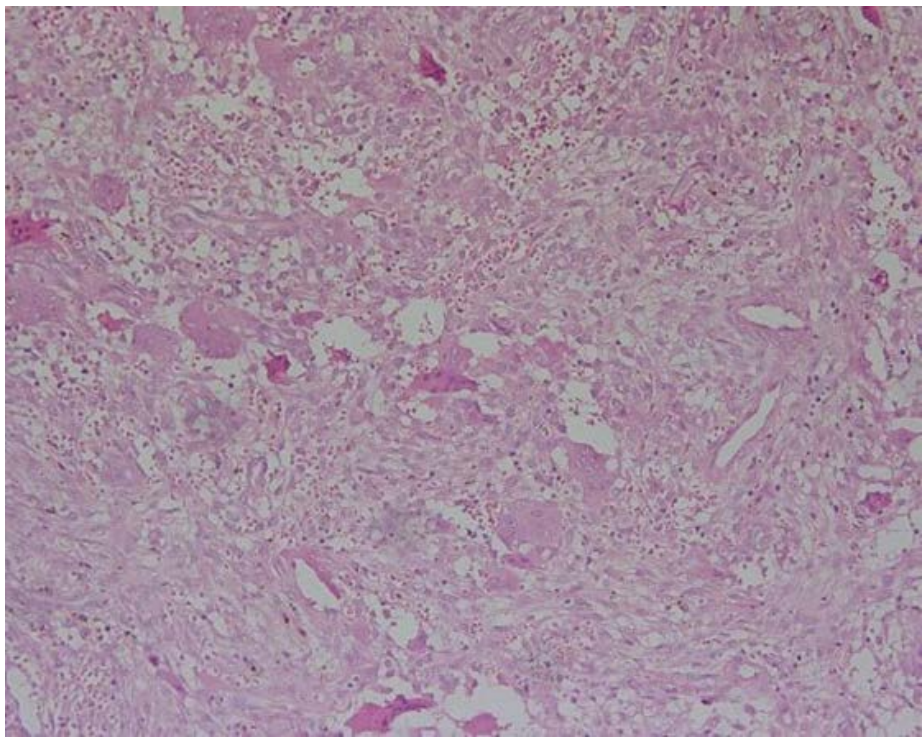

Figure 6. H \& E staining image.

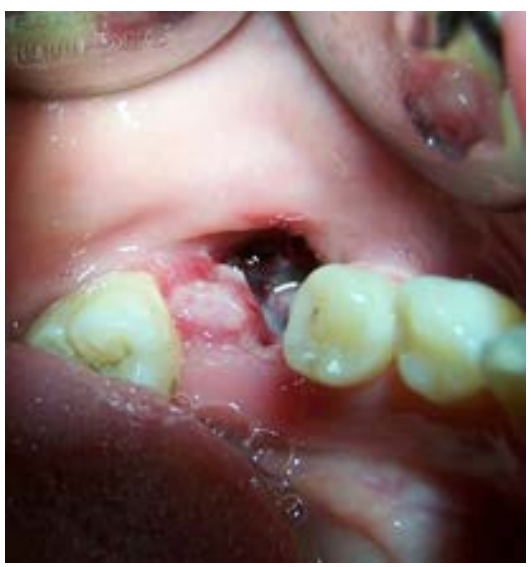

(a)

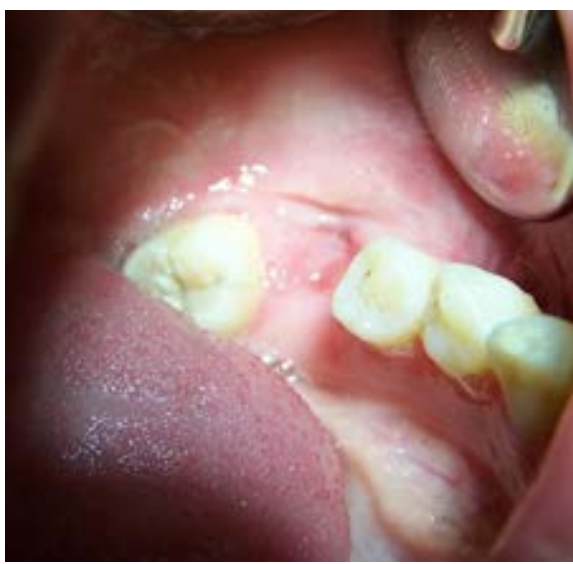

(b)

Figure 7. (a) Healing 15 days (b) Healing 60 days.

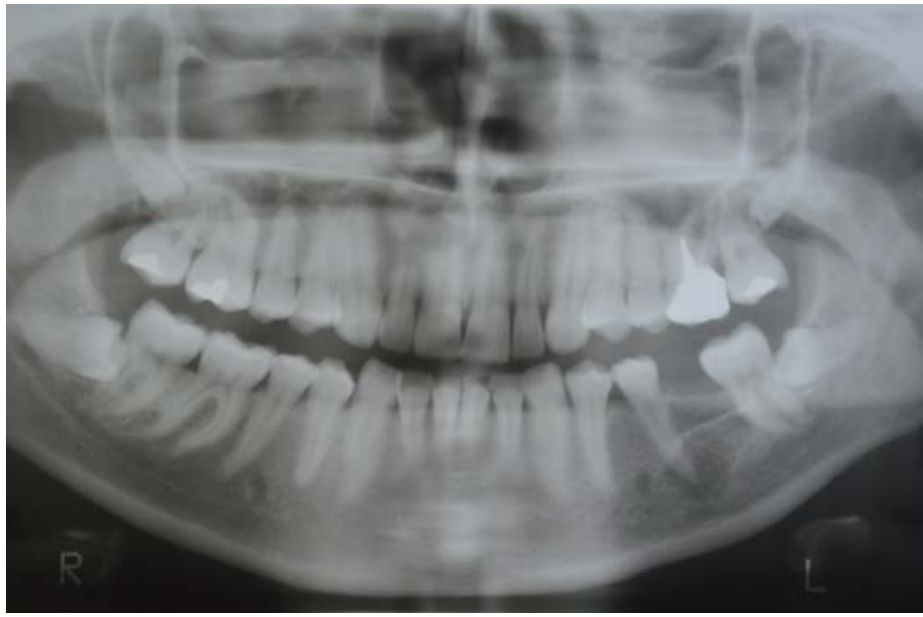

Figure 8. 1-year Rx control shows a small radiolucent area below the root apex of the second premolar. 


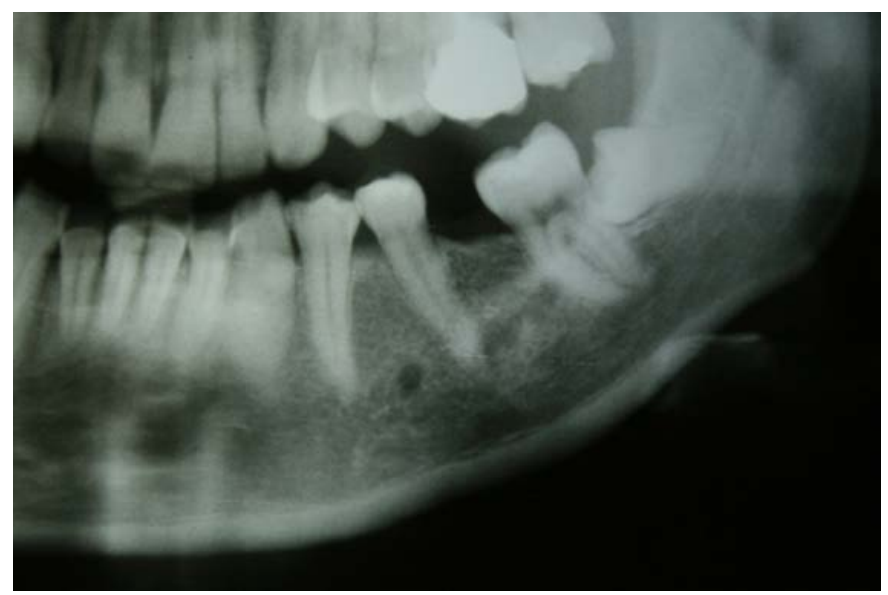

Figure 9. Control 5 years shows an image of normal bone regeneration with reduction of the interdental mesiodistal space.

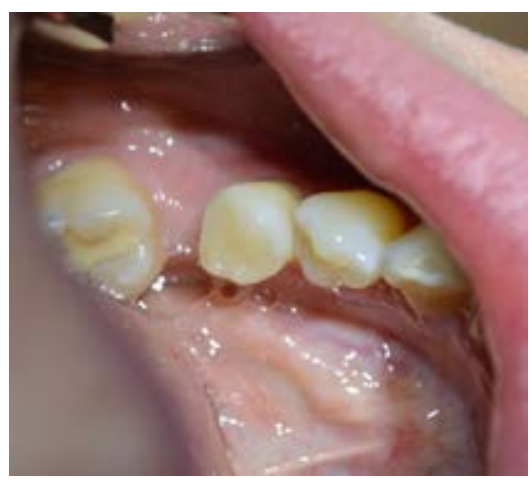

(a)

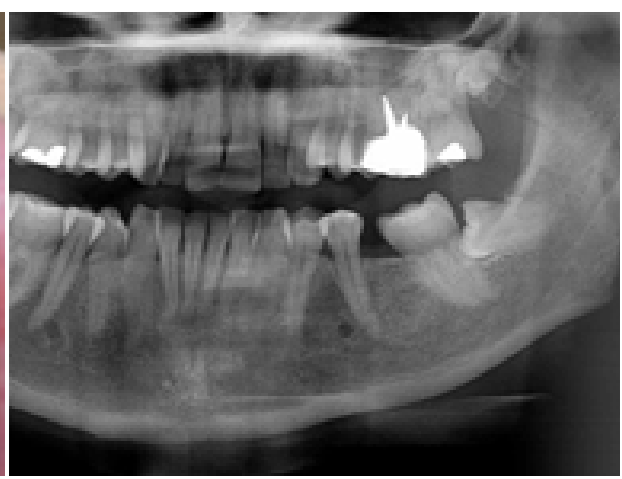

(b)

Figure 10. In the clinical (a) and radiographic (orthopantomography) (b) control at 15 years, no signs of recurrence were observed, showing a mesialized second molar and the closure of the space occupied by the first molar involved in the tumor lesion. (See figures $7 \mathrm{~b}$ and $4 \mathrm{~b}$ to compare both images respectively).

The study of the clinical behavior of CGCG is key to be able to diagnose the injury. According to the clinical and radiographic characteristics, CGCG in most cases presents in a non-aggressive way, exhibiting slow growth, generally asymptomatic, does not perforate the cortical bone, and does not induce root resorption, presenting low recurrence rates after treatment. These characteristics coincide with the present clinical case, which after being diagnosed was classified as non-aggressive because it did not present painful symptoms, perforation of the cortical bone or involvement of adjacent teeth. The aggressive form of the lesion is less common and is characterized by faster growth, showing a higher recurrence rate, a greater tendency for root resorption and painful symptoms [11].

Asymptomatic lesions can go unnoticed for years, usually detected on routine radiographic examination or due to painless bone expansion [4]. Our clinical case is in agreement with this statement, since the patient did not report painful symptoms, however, she presented clinical facial alterations in the region of the injury (mandibular swelling), which caught the patient's attention and was the 
reason for her consultation. For this reason, the moment of origin and the time of evolution of the lesion are unknown. In cases of CGCG pathology with symptoms, patients may present mainly pain, dental mobility with root resorption and rapid growth of the lesion [12].

The radiological evaluation of the CGCG is not pathognomonic, therefore probable differential diagnoses are postulated [13]. In the reported clinical case, the lesion presented a multilocular and radiolucent form, respecting the integrity of the cortical bone.

These findings are in agreement with different authors who confirm that the radiographic characteristics of CGCG are usually presented as multilocular or in some cases unilocular radiolucency [4] [7] [8] [14].

The use of computed tomography facilitates the diagnosis, the exact location and extent of the pathology and its relationship with adjacent noble structures, which can demonstrate the aggressiveness of the lesion [9] [11]. In our case, at the time of surgery, we could not count on this diagnostic tool.

The choice of the ideal therapy selected is controversial, since different alternatives are presented in the literature, however factors such as the age of the patient, location and extent of the lesion, clinical characteristics and aggressiveness are decisive [15].

Conventional treatment of CGCG is "in toto" surgical excision of the lesion [8] [16]. Case reports indicate that it can be treated with simple curettage or surgical enucleation without bone grafting [17].

In the histopathological examination, a stroma consisting of a regular amount of fibrous cell-spindle tissue with intense tumor vascularization formed by newly formed capillaries, a large number of multinucleated giant cells of homogeneous or slightly granular cytoplasm, with numerous nuclei identical to stromal cells generally grouped in the center of the cytoplasm, osteoclastoid in appearance. These characteristics are consistent with the findings of Kruse-lösler et al. and Eckardt et al. [9] [18] Vered et al. who affirm that giant cells have intermediate or similar characteristics to osteoclasts and macrophages [19] and Neville et al. [4] states that there is evidence that giant cells would be functional osteoclasts. These authors also affirm that the CGCG of aggressive and non-aggressive behavior show very similar histological findings and Chuong et al. assures that there are no histological differences between the aggressive and non-aggressive types of the lesion [11]. Due to this evident difficulty in the accurate diagnosis of the behavior of the lesion and coinciding with other authors, we propose the use of complementary treatments to the surgical treatment to reduce the recurrence rates of the lesion such as peripheral ostectomy, Carnoy's solution, liquid nitrogen and cryotherapy [20] [21] [22].

In the reported case, the collaboration of the low-income patient allowed ambulatory surgery to be performed under local anesthesia with a conservative curettage procedure and irrigation with Carnoy's solution with minimal morbidity, maximum tissue preservation, and respect for adjacent noble structures (lower dental nerve) that retained their integrity. 
The placement of iodoformed gauze as a filler for the bone defect facilitates healing by second intention and is inexpensive but optimal bone rehabilitation is not achieved. To improve bone regeneration in large cysts and tumors, new low-cost bone grafts are currently being developed to fill in extensive bone defects after surgery [23] [24].

The recurrence rates reported in the literature are in a wide variable range between $10 \%$ to $50 \%$ of cases and the number of recurrences of the lesion is inversely proportional to the age of the patient, that is, young people have more recurrences. [4] [25] In addition, mandible lesions have a higher number of recurrences than the upper jaw, and the aggressive form of the lesion has a higher recurrence rate after treatment [9] [11] [12] [25]. The case reported in this study was diagnosed and treated in 2005. The fundamental difference with other cases presented is the performance of ambulatory surgery and it is also the first documented case of a central giant cell granuloma with prolonged radiographic clinical follow-up of the injury for 15 years with regeneration of normal bone tissue and absence of recurrence.

\section{Conclusion}

The CGCG requires the initial study of the images to make a differential diagnosis with different intraosseous pathologies. Observation of clinical characteristics and prudence is convenient in planning the treatment of these lesions. A prior puncture biopsy is recommended for the definitive histopathological diagnosis and the best possible treatment. The current impossibility of diagnosing with certainty the potential aggressiveness of the lesion reinforces the use of our minimally invasive surgical protocol with Carnoy's solution to avoid recurrences.

\section{Acknowledgements}

The authors gratefully acknowledge the pathological anatomy laboratory Dr. Ricardo Assayas and the surgical assistants María Inés Cabrera and Yanina Solera.

\section{Conflicts of Interest}

The authors declare no conflicts of interest regarding the publication of this paper.

\section{References}

[1] Barnes, L., Eveson, J.W., Reichart, P. and Sidransky, D. (2005) Pathology and Genetics of Head and Neck Tumours. WHO/IARC Classification of Tumours. 3th Edition, Vol. 9, WHO Press, Geneva.

[2] El-Naggar, A.K., Chan, J.K.C., Grandis, J.R., Takata, T. and Slootweg, P.J. (2017) Classification of Head and Neck Tumours. WHO/IARC Classification of Tumours. 4th Edition, Vol. 9, WHO Press, Geneva.

[3] Kramer, I.R., Pindborg, J.J. and Shear, M. (1991) Histological Typing of Odontogenic Tumors. 2nd Edition, Springer-Verlag, Berlin, 31.

https://doi.org/10.1007/978-3-662-02858-2 
[4] Neville, B.W., Damm, D.D., Allen, C.M. and Bouquot, J.E. (2009) Oral and Maxillofacial Pathology. 3rd Edition, Elsevier, Rio de Janeiro.

[5] Kauzman, A., Li, S.Q., Bradley, G., Bell, R.S., Wunder, J.S., Kandel, R., et al. (2004) Central Giant Cell Granuloma of the Jaws: Assessment of Cell Cycle Proteins. Journal of Oral Pathology \& Medicine, 33, 170-176.

https://doi.org/10.1111/j.0904-2512.2004.00101.x

[6] Waldron, C.A. and Shafer, W.G. (1966) The Central Giant Cell Reparative Granuloma of the Jaws. An Analysis of 38 Cases. American Journal of Clinical Pathology, 45, 437-447. https://doi.org/10.1093/ajcp/45.4.437

[7] Cohen, M.A. and Hertzanu, Y. (1988) Radiologic Features, Including Those Seen with Computed Tomography, of Central Giant Cell Granuloma of the Jaws. Oral Surgery Oral Medicine and Oral Pathology, 65, 255-261.

https://doi.org/10.1016/0030-4220(88)90176-4

[8] Whitaker, S.B. and Waldron, C.A. (1993) Central Giant Cell Lesions of the Jaws. Oral Surgery, Oral Medicine, Oral Pathology, Oral Radiology, and Endodontology, 75, 199-208. https://doi.org/10.1016/0030-4220(93)90094-K

[9] Kruse-Lösler, B., Diallo, R., Gaertner, C., Mischke, K.L., Joos, U., Kleinheinz, J., et al. (2006) Central Giant Cell Granuloma of the Jaws: A Clinical, Radiologic, and Histopathologic Study of 26 Cases. Oral Surgery, Oral Medicine, Oral Pathology, Oral Radiology, and Endodontology, 101, 346-354. https://doi.org/10.1016/j.tripleo.2005.02.060

[10] Austin, L.T., Dahlin, D.C. and Royer, R.Q. (1959) Giant-Cell Reparative Granuloma and Related Conditions Affecting the Jawbones. Oral Surgery Oral Medicine and Oral Pathology, 12, 1285-1295. https://doi.org/10.1016/0030-4220(59)90215-4

[11] Chuong, R., Kaban, L.B., Kozakewich, H. and Pérez-Atayde, A. (1986) Central Giant Cell Lesions of the Jaws: A Clinicopathologic Study. Journal of Oral and Maxillofacial Surgery, 44, 708-713. https://doi.org/10.1016/0278-2391(86)90040-6

[12] Bataineh, A.B., Al-Khateeb, T. and Rawashdeh, M.A. (2002) The Surgical Treatment of Central Giant Cell Granuloma of the Mandible. Journal of Oral and Maxillofacial Surgery, 60, 756-761. https://doi.org/10.1053/joms.2002.33241

[13] Theodorou, D.J. and Theodorou, S.J. (2003) Primary Non-Odontogenic Tumors of the Jaw Bones: An Overview of Essential Radiographic Findings. Clinical Imaging, 27, 59-70. https://doi.org/10.1016/S0899-7071(02)00518-1

[14] Sidhu, M.S., Parkash, H. and Sidhu, S.S. (1995) Central Giant Cell Granuloma of Jaws: Review of 19 Cases. British Journal of Oral and Maxillofacial Surgery, 33, 43-46. https://doi.org/10.1016/0266-4356(95)90086-1

[15] Carlos, R. and Sedano, H.O. (2002) Intralesional Corticosteroids as an Alternative Treatment for Central Giant Cell Granuloma. Oral Surgery, Oral Medicine, Oral Pathology, Oral Radiology, and Endodontology, 93, 161-166. https://doi.org/10.1067/moe.2002.119971

[16] Adornato, M.C. and Paticoff, K.A. (2001) Intralesional Corticosteroid Injection for Treatment of Central Giant-Cell Granuloma. The Journal of the American Dental Association, 132, 186-190. https://doi.org/10.14219/jada.archive.2001.0153

[17] Üstündağ, E., Iseri, M., Keskin, G. and Müezzinoğlu, B. (2002) Central Giant Cell Granuloma. International Journal of Pediatric Otorhinolaryngology, 65, 143-146. https://doi.org/10.1016/S0165-5876(02)00118-0

[18] Eckardt, A., Pogrel, M.A., Kaban, L.B., Chew, K. and Mayall, B.H. (1989) Central Giant Cells Granuloma of the Jaws. International Journal of Oral and Maxillofacial Surgery, 18, 3-6. https://doi.org/10.1016/S0901-5027(89)80004-9 
[19] Vered, M., Buchner, A. and Dayan, D. (2006) Immunohistochemical Expression of Glucocorticoid and Calcitonin Receptors as a Tool for Selecting Therapeutic Approach in Central Giant Cell Granuloma of the Jawbones. International Journal of Oral and Maxillofacial Surgery, 35, 756-760.

https://doi.org/10.1016/j.ijom.2006.02.014

[20] Webb, D.J. and Brockbank, J. (1986) Combined Curettage and Cryosurgical Treatment for the Aggressive "Giant Cell Lesion" of the Mandible. International Journal of Oral and Maxillofacial Surgery, 15, 780-785.

https://doi.org/10.1016/S0300-9785(86)80124-7

[21] Pogrel, M.A. (2003) Calcitonin Therapy for Central Giant Cell Granuloma. Journal of Oral and Maxillofacial Surgery, 61, 649-653.

https://doi.org/10.1053/joms.2003.50129

[22] Eisenbud, L., Stern, M., Rothberg, M. and Sachs, S.A. (1988) Central Giant Cell Granuloma of the Jaws: Experiences in the Management of Thirty-Seven Cases. Journal of Oral and Maxillofacial Surgery, 46, 376-384. https://doi.org/10.1016/0278-2391(88)90221-2

[23] Garcés-Villalá, M., Rico, S., Nazar, S., Escudero-Pinel, M., Galván-Josa, V. and Calvo-Guirado, J. (2020) Evaluation of Two Highly Porous Microcrystalline Biphasic Calcium Phosphate-Based Bone Grafts for Bone Regeneration: An Experimental Study in Rabbits. Journal of Materials Science and Chemical Engineering, 8, 8-30. https://doi.org/10.4236/msce.2020.86002

[24] Garcés Villalá, M.A., Calvo Guirado, J.L., Granados, D., Limandri, S.P. and Galván Josa, V. (2017) Synthesis, Chemical and Microstructural Characterization of Micro Macroporous Biphasic Calcium Phosphate Granules. X-Ray Spectrometry, 46, 237-241. https://doi.org/10.1002/xrs.2762

[25] de Lange, J., Rosenberg, A.J., van den Akker, H.P., Koole, R., Wirds, J.J., van den Berg, H., et al. (1999) Treatment of Central Giant Cell Granuloma of the Jaw with Calcitonin. International Journal of Oral and Maxillofacial Surgery, 28, 372-376. https://doi.org/10.1016/S0901-5027(99)80086-1 